\title{
Effects of sevoflurane and propofol on the optic nerve sheath diameter in patients undergoing laparoscopic gynecological surgery: a randomized controlled clinical studies
}

\author{
Weilian Geng ${ }^{1 \dagger}$, Changxing Chen ${ }^{2 \dagger}$, Xingfeng Sun $^{1}$ and Shaoqiang Huang ${ }^{1 *}$ (i)
}

\begin{abstract}
Background: The results of studies on changes in intracranial pressure in patients undergoing laparoscopic surgery are inconsistent. Meanwhile, previous neurosurgery studies have suggested that propofol and sevoflurane have inconsistent effects on cerebral blood flow and cerebrovascular self-regulation. The purpose of this study is to compare changes in the optic nerve sheath diameter in patients undergoing laparoscopic gynecological surgery under anesthetic maintenance with propofol versus sevoflurane.

Methods: This study included 110 patients undergoing laparoscopic gynecological surgery with an estimated operative time of more than $2 \mathrm{~h}$ under general anesthesia. The study was a randomized controlled study. The optic nerve sheath diameter (ONSD) at various time points was measured by ultrasound, including when the patients entered the operating room (Tawake), after successful anesthesia induction and endotracheal intubation (Tinduction), when the body position was adjusted to the Trendelenburg position and the $\mathrm{CO}_{2}$ pneumoperitoneum pressure reached $14 \mathrm{mmHg}$, which was recorded as $T_{0}$. Then, measurements were conducted every $15 \mathrm{~min}$ for the first $1 \mathrm{~h}$ and then once every hour until the end of the surgery $\left(T_{15}, T_{30}, T_{45}, T_{1 \mathrm{~h}}, T_{2} \mathrm{~h} \ldots\right)$, after the end of surgery and the tracheal tube was removed ( $\left.T_{\text {end }}\right)$, and before the patients were transferred to the ward ( $\left.T_{\text {pacu }}\right)$.

Results: A significant difference in optic nerve sheath diameter was found between two groups at $T_{15}, T_{30}, T_{45}$ $(4.64 \pm 0.48 \mathrm{~mm}$ and $4.50 \pm 0.29 \mathrm{~mm}$, respectively, $p=0.031 ; 4.77 \pm 0.45 \mathrm{~mm}$ and $4.62 \pm 0.28 \mathrm{~mm}$, respectively, $p=$ $0.036 ; 4.84 \pm 0.46 \mathrm{~mm}$ and $4.65 \pm 0.30 \mathrm{~mm}$, respectively, $p=0.012$ ), while there was no significant difference at $T_{\text {awake }}$ and other time points.

Conclusion: During laparoscopic gynecological surgery lasting more than $2 \mathrm{~h}$, the optic nerve sheath diameter was slightly larger in the propofol group than that in the sevoflurane group in the first $45 \mathrm{~min}$. No significant difference was observed between the two groups $1 \mathrm{~h}$ after surgery.

(Continued on next page)
\end{abstract}

\footnotetext{
* Correspondence: drhuangsq@163.com

${ }^{\dagger}$ Weilian Geng and Changxing Chen contributed equally to this work.

'Department of Anesthesia, Obstetrics and Gynecology Hospital of Fudan University, No.128, Shenyang RD, Yangpu district, Shanghai 200090, China

Full list of author information is available at the end of the article
}

(c) The Author(s). 2021 Open Access This article is licensed under a Creative Commons Attribution 4.0 International License, which permits use, sharing, adaptation, distribution and reproduction in any medium or format, as long as you give appropriate credit to the original author(s) and the source, provide a link to the Creative Commons licence, and indicate if changes were made. The images or other third party material in this article are included in the article's Creative Commons licence, unless indicated otherwise in a credit line to the material. If material is not included in the article's Creative Commons licence and your intended use is not permitted by statutory regulation or exceeds the permitted use, you will need to obtain permission directly from the copyright holder. To view a copy of this licence, visit http://creativecommons.org/licenses/by/4.0/ The Creative Commons Public Domain Dedication waiver (http://creativecommons.org/publicdomain/zero/1.0/) applies to the data made available in this article, unless otherwise stated in a credit line to the data. 
(Continued from previous page)

Trial registration: clinicaltrials.gov, NCT03498235. Retrospectively registered 1 March 2018.

The manuscript adheres to CONSORT guidelines.

Keywords: Optic nerve sheath diameter, ONSD, sevoflurane, Propofol, $\mathrm{CO}_{2}$ pneumoperitoneum, Trendelenburg position

\section{Background}

During laparoscopic gynecological surgery, due to the $\mathrm{CO}_{2}$ pneumoperitoneum and the steep Trendelenburg position (with the head lowered 45 degrees and the feet raised), cerebral venous recirculation becomes obstructed, and cerebral venous pressure increases. Meanwhile, intraabdominal pressure increases, cerebrospinal fluid (CSF) absorption decreases, and intracranial pressure increases $[1,2]$. The $\mathrm{CO}_{2}$ pneumoperitoneum causes hypercapnia, cerebrovascular dilation, increased intracranial cerebral blood flow, and increased intracranial pressure [3]. Although these effects rarely result in serious neurological complications such as cerebral haemorrhage and cerebral oedema [4], mild neurological complications, such as nausea, vomiting, and headaches, occur sometimes [5].

The results of different studies on changes in intracranial pressure in patients undergoing laparoscopic surgery are not consistent. Kim et al. compared patients undergoing laparoscopic gynecological surgery and laparoscopic gallbladder surgery under desflurane anesthesia and found that the pneumoperitoneum can cause a slight increase in intracranial pressure, but body position did not affect intracranial pressure, and intracranial pressure quickly returned to normal [6]. In a study of patients undergoing robot-assisted laparoscopic prostate surgery under sevoflurane anesthesia, Verdonck et al. found that optic nerve sheath diameter (ONSD) remained unchanged throughout the perioperative period [7].

Propofol and sevoflurane are commonly used anesthetic drugs. Previous neurosurgery studies have suggested that the two drugs have inconsistent effects on cerebral blood flow and cerebrovascular selfregulation [8]. Propofol dose-dependently contracts cerebral blood vessels, inhibits the cerebral oxygen metabolic rate, and reduces intracranial pressure $[9,10]$ but does not affect self-regulation of cerebral blood flow or the responsiveness of cerebral blood vessels to $\mathrm{CO}_{2}$ [11, 12]. Unlike propofol, the effect of sevoflurane on cerebral blood vessels depends on the balance between the direct vasodilating effect and the vasoconstricting effect caused by the reduction in cerebral metabolism [13]. Meanwhile, sevoflurane at a minimum alveolar concentration (MAC) of 0.5-1.5 does not affect self-regulation of cerebral blood flow or the reactivity of cerebral blood vessels to $\mathrm{CO}_{2}[14,15]$. It is unclear whether different anesthetic drugs have different effects on intracranial pressure because of the postural position and $\mathrm{CO}_{2}$ pneumoperitoneum in laparoscopic gynecological surgery.

The optic nerve sheath is a continuation of the cerebral dura mater with a transverse subarachnoid space, and its cerebrospinal fluid is also connected to the intracranial subarachnoid space. Therefore, when intracranial pressure increases, ONSD increases [16]. By artificially changing intracranial pressure, Hansen et al. [17] found that there is positive correlation between intracranial pressure and ONSD. Maissan et al. [18] believed that the ONSD could reflect changes in intracranial pressure in real time.

Compared with invasive intracranial pressure measurement, the ONSD measured by ultrasound is simpler, non-invasive, and convenient for bedside examination, and changes in intracranial pressure can be observed at any time $[18,19]$. The purpose of this study is to compare the effects of propofol and sevoflurane on ONSD in patients undergoing laparoscopic gynecological surgery.

\section{Methods}

This is a randomized controlled clinical trial. The ethics committee of Obstetrics and Gynaecology Hospital of Fudan University approved this study. The study was registered with clinicaltrials.gov (NCT03498235). A total of 110 patients who were classified as class I-II according to the standards and guidelines of the American Society of Anaesthesiologists (ASA) and underwent elective laparoscopic gynecological surgery under general anesthesia for an estimated operative time $>2 \mathrm{~h}$ from February 2018 to June 2020 were included in the study. The patients were randomly divided into the propofol group (Group P) or the sevoflurane group (Group S). Patients were randomized in a 1:1 ratio occurred by computerized sequence generation. An anesthesiologist, who was not involved in the study, created sealed opaque envelopes in which groupings were written randomized. Envelopes were opened in sequential order only after a patient had signed the consent form. The exclusion criteria were as follow: operative time $<2 \mathrm{~h}$; body mass index $(\mathrm{BMI})<18.5 \mathrm{~kg} / \mathrm{m}^{2}$ or $\geq 24 \mathrm{~kg} / \mathrm{m}^{2}$; liver or kidney disease or abnormal results for related laboratory tests (C-reactive protein, hemoglobin, electrolytes, liver and kidney function, international normalized ratio, etc.); 
neuromuscular disease; allergies to anesthetics; pregnancy; and ophthalmological diseases.

The patients did not receive any preoperative drugs and were routinely monitored for non-invasive blood pressure, electrocardiography, and oxygen saturation. All patients received propofol, sufentanil $0.5 \mu \mathrm{g} / \mathrm{kg}$ and cisatracurium $0.1 \mathrm{mg} / \mathrm{kg}$ by intravenous injection for anesthesia induction and endotracheal intubation. TCI system was used for propofol, the target concentrations of propofol during anesthesia induction and maintenance were $4 \mu \mathrm{g} / \mathrm{ml}$ and $3.2 \mu \mathrm{g} / \mathrm{ml}$, respectively. After successful intubation, mechanical ventilation was initiated in volumetric control mode, with a tidal volume of 6-8 $\mathrm{ml} / \mathrm{kg}$ and a respiratory rate of $10-12$ breaths/minute while no PEEP in all patients. The tidal volume and respiratory rate were adjusted to maintain an end-tidal $\mathrm{CO}_{2}$ of $35-40 \mathrm{mmHg}$. In the sevoflurane group, sevoflurane was maintained at 1-1.5 minimal alveolar concentration (MAC) in 50\% oxygen/ air. Remifentanil at $0.25 \mu \mathrm{g} \cdot \mathrm{kg}^{-1} \cdot \mathrm{min}^{-1}$ and intermittent cisatracurium injections were used for anesthetic maintenance. The infusion rate of propofol or the concentration of sevoflurane was adjusted according to a Bispectral index (BIS) of 40-60. Thirty minutes before the end of the surgery, ondansetron was administered to prevent postoperative nausea and vomiting, and $4 \mathrm{mg}$ of oxycodone was administered intravenously to relieve postoperative pain. The medications were discontinued immediately upon completion of the surgery. When the patient was awake, the tidal volume was greater than $6 \mathrm{~L} / \mathrm{min}$, and the respiratory rate was $14 \sim 20$ breaths/min with no PEEP; the endotracheal tube had been removed. Afterwards, the endotracheal tube was removed, the patient was routinely monitored in the post-anesthetic recovery room (PACU) for $1 \mathrm{~h}$.

If the intraoperative mean arterial pressure (MAP) was lower than $90 \mathrm{mmHg}$ or decreased by $>30 \%$ from the baseline value, then a bolus of $100 \mu \mathrm{g}$ of phenylephrine was administered. If the heart rate was less than 50 beats/minute, then $0.5 \mathrm{mg}$ of atropine was administered. The angle of the Trendelenburg position adopted in the operation was $30^{\circ}$, and the $\mathrm{CO}_{2}$ pneumoperitoneum pressure was maintained at $14 \mathrm{mmHg}$. Patients were excluded from analysis due to intraoperative changes in surgical methods, such as conversion to vaginal surgery or transabdominal surgery, subcutaneous carbon dioxide emphysema development intraoperatively, and intraoperative changes in the anesthetic maintenance drugs.

Ultrasound (SonoSite M-Turbo, USA) was used for ONSD measurement. The patient assumed the supine position with the head in the middle position and the eyes gently closed. A disposable transparent patch was used to protect patient's eyes. An ultrasound-coupling agent was evenly applied to both eyes and the ultrasonic probe. The $6-15 \mathrm{~Hz}$ high-frequency ultrasonic probe was gently placed above the upper eyelids without applying pressure to the globe. On the ultrasound screen, we can see a "long strip" hypoechoic area, which is perpendicular to the eyeball. The sheath structure with high echo can be seen at the edge of hypoechoic area. ONSD refers to the distance between the high echo sheath structures. The ONSD was measured at $3 \mathrm{~mm}$ behind the lateral edge of eyeball.

The images of left and right eyes were obtained three times separately at one time point, and all images were stored in DICOM and jpeg formats. A trained anaesthesiologist who was blinded for group allocation took the images of optic nerve sheath in all patients in this study, and ONSD was measured based on stored images by an experienced ultrasound doctor, and the average value was taken, with an accuracy of $0.1 \mathrm{~mm}$. Previous studies have suggested that no significant difference in ONSD exists between different surveyors [20], and trained doctors can also accurately measure the ONSD by ultrasound at the bedside [21].

The primary outcome is to compare the effects of propofol and sevoflurane on ONSD at different time points. The time points at which the ONSD was ultrasonically measured were when the patients entered the operating room $\left(\mathrm{T}_{\text {awake }}\right)$, after anesthesia induction and endotracheal intubation ( $\left.\mathrm{T}_{\text {induction }}\right)$, and when the body position was adjusted to the Trendelenburg position and the $\mathrm{CO}_{2}$ pneumoperitoneum pressure reached 14 $\mathrm{mmHg}$, which was recorded as $\mathrm{T}_{0}$. Then, the ONSD was measured every $15 \mathrm{~min}$ for the first hour followed by every hour until the end of the surgery $\left(T_{15}, T_{30}, T_{45}\right.$, $\left.\mathrm{T}_{1 \mathrm{~h}}, \mathrm{~T}_{2 \mathrm{~h}} \ldots\right)$, after anesthesia and drug discontinuation and extubation ( $\mathrm{T}_{\text {end }}$ ), and immediately before transfer from the anesthesia recovery room to the ward $\left(\mathrm{T}_{\mathrm{pacu}}\right)$. Each time that the ONSD was measured by ultrasound, MAP and BIS was recorded.

\section{Statistical analysis}

The quantitative data with a normal distribution were expressed as the mean \pm standard deviation, while the quantitative data with a non-normal distribution were expressed as the median (interquartile range, IQR). Analysis of variance was conducted on repeated measurement data within the groups, and the StudentNewman-Keuls (SNK) q test was used for comparisons between the two groups. $P$ values were adjusted by Bonferroni correction. $P<0.05$ was considered statistically significant.

\section{Calculation of sample size}

The early stage of sample size calculation included $15 \mathrm{fe}-$ male patients in the preliminary experiment. The standard deviation of ONSD preoperatively when the patients 
were conscious was $0.42 \mathrm{~mm}$. According to the research results of Hansen et al. [17], every $1-\mathrm{mmHg}$ increase in intracranial pressure corresponds to a $0.025-\mathrm{mm}$ increase in the ONSD. Consistent with the study of Robba et al. [22], we believe that variation in the ONSD greater than $0.25 \mathrm{~mm}$ is clinically significant. At the levels of $\alpha=0.05$ and $\beta=0.1$, the sample size of each group was calculated to be at least 48 cases. Considering the likelihood that approximately $25 \%$ of the patients would withdraw from the study, 60 cases were needed for each group.

\section{Results}

Among the 120 female patients who underwent elective laparoscopic gynecological surgery, due to not meeting inclusion criteria or refusing to participate, 116 patients were included in this study, with 58 patients in each group. Due to $\mathrm{CO}_{2}$ pneumoderma or changes in surgical methods, 55 cases in each group were finally analysed (Fig. 1). The general conditions of the patients are shown in Table 1.

The comparison of the ONSD at each time point between the two groups is shown in Table 2 and Fig. 2. No significant difference in the baseline preoperative ONSD was found between the two groups. After anesthesia induction, the ONSD values all decreased compared to the baseline value in both two groups, but no significant differences between the two groups. At three time points $\left(\mathrm{T}_{\text {awake, }}, \mathrm{T}_{\text {induction }}\right.$, and $\left.\mathrm{T}_{0}\right)$, the ONSD was not significantly different between the two groups $(p=0.984,0.666$, and 0.646 , respectively). Over time, at
Table 1 Baseline Characteristics

\begin{tabular}{llll}
\hline & Group P $(\boldsymbol{n}=\mathbf{5 5})$ & Group S $(\boldsymbol{n}=\mathbf{5 5})$ & $\boldsymbol{P}$ \\
\hline Age $(\mathrm{y})$ & $40.53 \pm 11.08$ & $41.15 \pm 10.26$ & 0.762 \\
Height $(\mathrm{cm})$ & $161.18 \pm 4.20$ & $159.79 \pm 4.50$ & 0.097 \\
Weight $(\mathrm{kg})$ & $59(54.5,63)$ & $56(51.9,60)$ & 0.057 \\
BMl $(\mathrm{kg} / \mathrm{m} 2)$ & $22.74 \pm 2.28$ & $22.31 \pm 2.15$ & 0.262 \\
Surgery duration $(\mathrm{h})$ & $2.33(2.12,2.75)$ & $2.5(2.22,2.75)$ & 0.165 \\
Total blood loss $(\mathrm{ml})$ & $100(50,120)$ & $80(50,100)$ & 0.424 \\
Urine volume $(\mathrm{ml})$ & $400(300,500)$ & $400(400,500)$ & 0.088 \\
Fluid volume $(\mathrm{ml})$ & $1200(1100,1500)$ & $1200(1100,1500)$ & 0.645 \\
Airway pressure $(\mathrm{mmHg})$ & $15(13,16)$ & $15(13,16)$ & 0.754 \\
\hline
\end{tabular}

The quantitative data with a normal distribution were expressed as mean \pm standard deviation.

The quantitative data with a non-normal distribution were expressed as median (interquartile range, IQR)

$B M I$ Body mass index

three time points $\left(\mathrm{T}_{15}, \mathrm{~T}_{30}\right.$, and $\left.\mathrm{T}_{45}\right)$, significant differences in ONSD were identified between the two groups $\left(p=0.031,0.035\right.$, and 0.028 , respectively). At $\mathrm{T}_{1 \mathrm{~h}}, \mathrm{~T}_{2 \mathrm{~h}}$, $\mathrm{T}_{\text {end }}$, and $\mathrm{T}_{\text {pacu, }}$, no significant differences in ONSD were found between the two groups after statistical correction ( $p=0.065,0.211,0.368$, and 0.646 respectively).

The comparison of the MAP and BIS at each time point between the two groups is shown in Fig. 3 and Fig. 4.There are no significant differences in MAP and BIS at each time point between Group P and Group S. No hypotension or serious neurological complications such as cerebral haemorrhage or cerebral oedema occurred in either group.

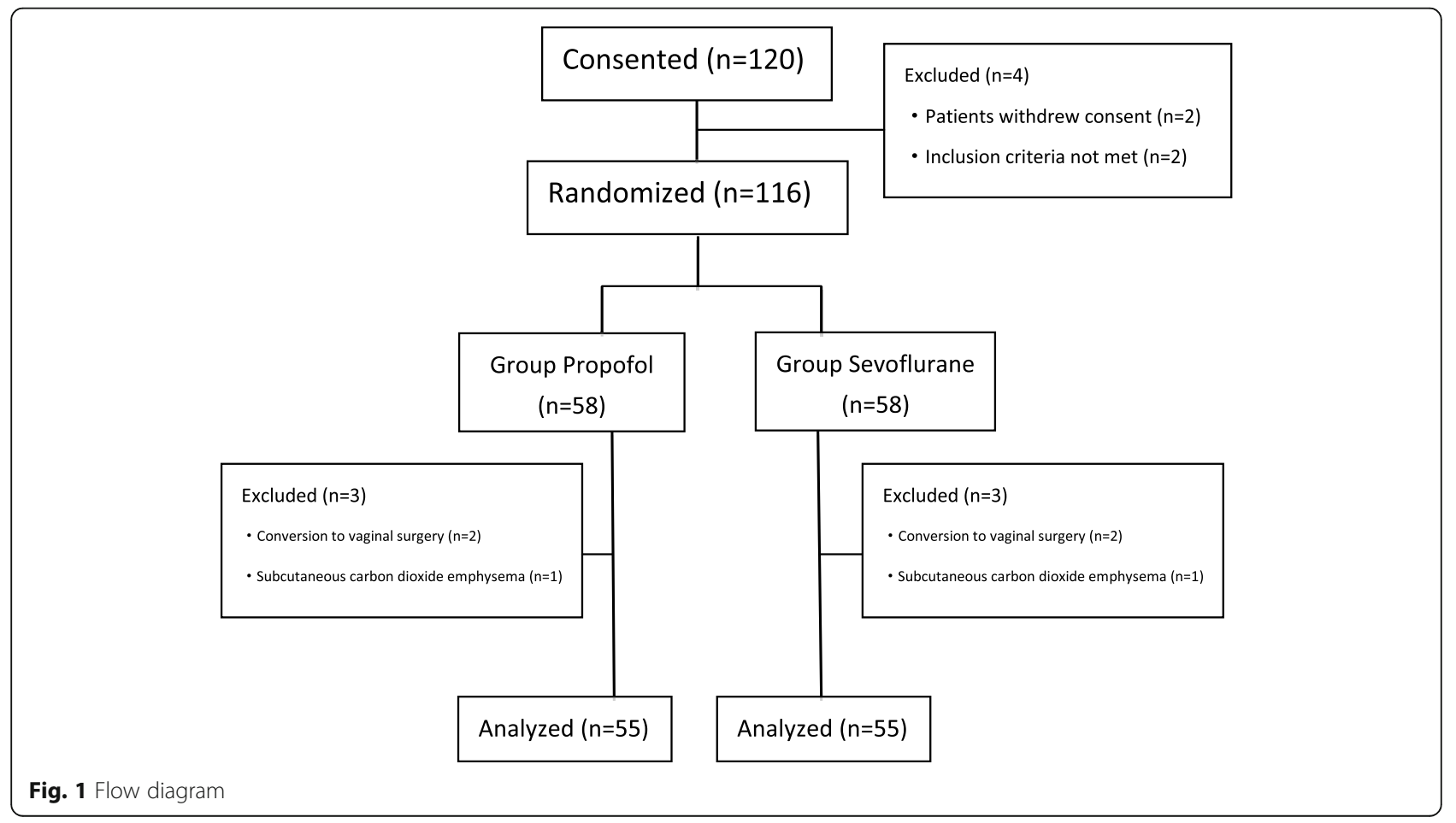


Table 2 Comparison of ONSD at different time points between two groups

\begin{tabular}{|c|c|c|c|}
\hline & Group P $(n=55)$ & Group S $(n=55)$ & $P$ \\
\hline ONSD T Tawake $(\mathrm{mm})$ & $4.39 \pm 0.37$ & $4.36 \pm 0.45$ & 0.694 \\
\hline ONSD $T_{\text {Induction }}(\mathrm{mm})$ & $4.06 \pm 0.45^{*}$ & $4.05 \pm 0.45^{*}$ & 0.882 \\
\hline ONSD T $(\mathrm{mm})$ & $4.53 \pm 0.47^{* \text { \#\# }}$ & $4.35 \pm 0.40^{* \#}$ & 0.058 \\
\hline ONSD $T_{15}(\mathrm{~mm})$ & $4.64 \pm 0.48^{* \#}$ & $4.50 \pm 0.29^{* \#}$ & 0.031 \\
\hline $\mathrm{ONSD}_{30}(\mathrm{~mm})$ & $4.77 \pm 0.45^{* \text { \# }}$ & $4.62 \pm 0.28^{* \#}$ & 0.036 \\
\hline ONSD T45 (mm) & $4.84 \pm 0.46^{* \#}$ & $4.65 \pm 0.30^{* \#}$ & 0.012 \\
\hline ONSD $\mathrm{T}_{1 \mathrm{~h}}(\mathrm{~mm})$ & $4.83 \pm 0.43^{* \#}$ & $4.66 \pm 0.28^{* \#}$ & 0.066 \\
\hline ONSD T $_{2 h}(\mathrm{~mm})$ & $4.82 \pm 0.41^{\text {*\# }}$ & $4.71 \pm 0.28^{* \#}$ & 0.089 \\
\hline ONSD $T_{\text {end }}(\mathrm{mm})$ & $4.84 \pm 0.44^{* \#}$ & $4.71 \pm 0.34^{* \#}$ & 0.082 \\
\hline ONSD T TACU $(\mathrm{mm})$ & $4.40 \pm 0.38^{* \#}$ & $4.36 \pm 0.35^{* \#}$ & 0.641 \\
\hline
\end{tabular}

Values were expressed as the mean \pm standard variation. * meant comparison of ONSD intra group at each time points to $T_{\text {awake. }}$ In Group $P$, values of $p$ were 0.000 except comparison of $T_{\text {pacu }}$ to $T_{\text {awake }}$ which $p$ value was 0.945 ; in Group $\mathrm{S}$, values of $p$ were $0.939 、 0.035$ and 0.884 when compared $\mathrm{T}_{0}, \mathrm{~T}_{15}$ and $T_{\text {pacu }}$ to $T_{\text {awake, }}$ while $p$ values were 0.000 at any other time points.\# meant comparison of ONSD intra group at each time points to $\mathrm{T}_{\text {induction, }}$ and all $p$ values were 0.000 in both two groups

\section{Discussion}

This study compared the effects of two general anesthesia drugs (propofol and sevoflurane) on the ONSD in patients undergoing laparoscopic gynecological surgery. The results showed that the ONSD was significantly reduced compared to the baseline value in the patients in the two groups after anesthesia induction and endotracheal intubation. With establishment of the $\mathrm{CO}_{2}$ pneumoperitoneum and the Trendelenburg position, the ONSD in both groups increased and exceeded the baseline value. However, at first $45 \mathrm{~min}$, the amplitude of the increase in the propofol group was greater than that in the sevoflurane group. Over time, considering the pneumoperitoneum and the Trendelenburg position, no significant difference in the ONSD was found between the two groups from $1 \mathrm{~h}$ after starting the surgery to extubation at the end of the surgery. When leaving the recovery room, the ONSD returned to baseline in the patients in both groups.

In this study, both groups received propofol and sufentanil for anesthesia induction, and cisatracurium was used for endotracheal intubation. Both sufentanil and propofol contract cerebral vessels and reduce the cerebral metabolic rate $[9,10,23]$; therefore, the ONSD after anesthesia induction was reduced compared to the baseline value.

With establishment of the $\mathrm{CO}_{2}$ pneumoperitoneum and the Trendelenburg position, the ONSD increased gradually but recovered to baseline by $1 \mathrm{~h}$ after surgery. The reason may be that the effect of the $\mathrm{CO}_{2}$ pneumoperitoneum and body position on intracranial pressure exceeds the effect of drugs on intracranial blood flow. Bilateral internal cervical vessels and vertebral vessels play an important role in cerebral circulation [24]. After establishment of the $\mathrm{CO}_{2}$ pneumoperitoneum and the Trendelenburg position, recirculation in the internal jugular vein and vertebral vein was obstructed. At the same time, the mean arterial pressure during establishment of the pneumoperitoneum and positioning was elevated compared to that after anesthesia induction. Whiteley et al. found that the ONSD was positively correlated with the mean arterial pressure [25].

For the propofol group, our results are basically consistent with those of Blecha et al. [26]; however, the amplitude of changes in the optic nerve sheath was

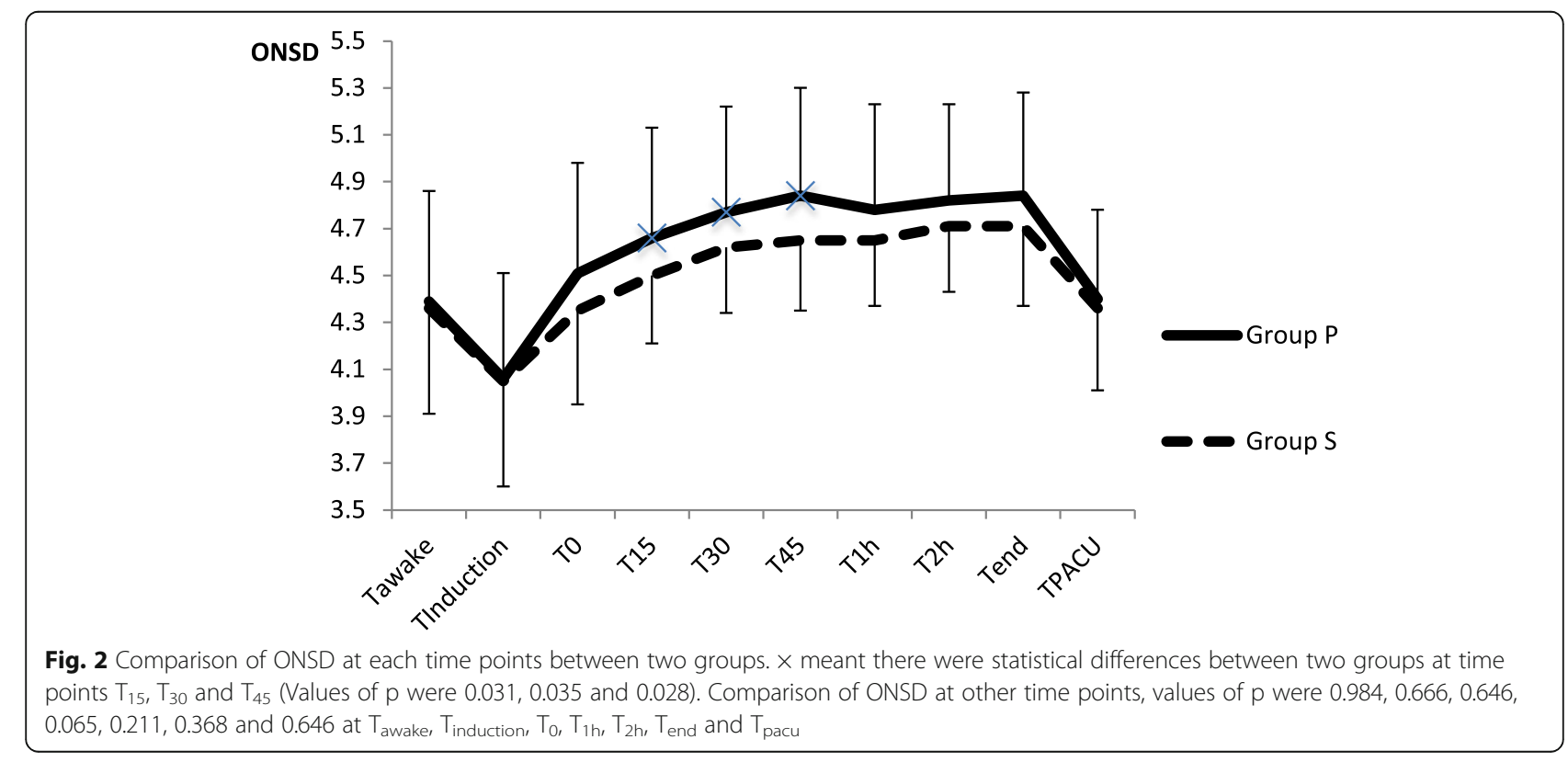




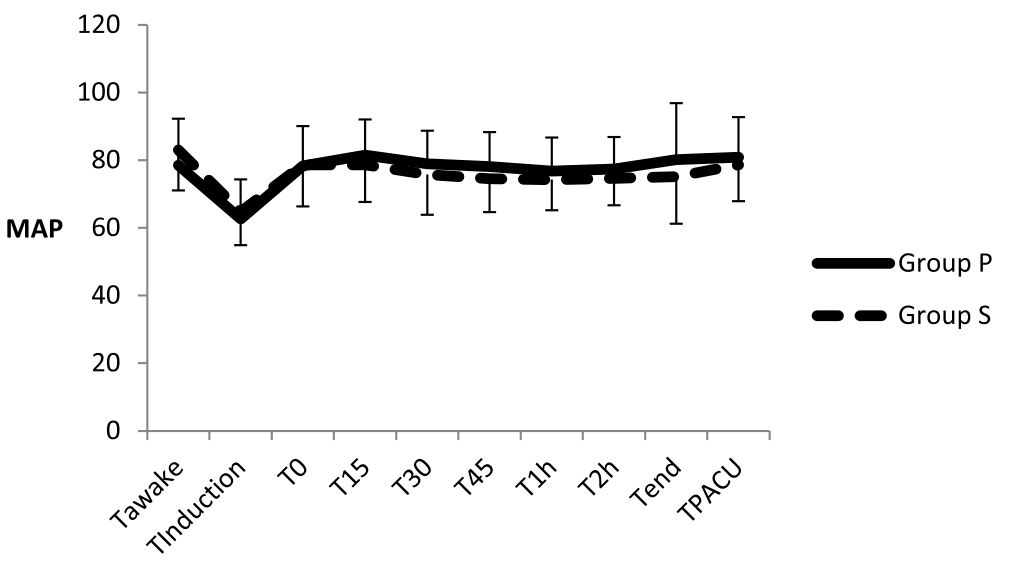

Fig. 3 Comparison of MAP at each time points between two groups. There are no significant differences between two groups at each time points (Values of $\mathrm{p}$ were $0.066,0.312,0.912,0.156,0.125,0.064,0.166,0.095,0.092$ and 0.290 ). MAP Mean arterial pressure

higher than that in the study of Blecha et al., and maybe the reason for the difference is that the patients in the study of Blecha et al. received midazolam before surgery, which can reduce intracranial pressure. In addition, the patients in that study were from western countries, and the ONSD varied among different races. Wang et al. found that among the Chinese population, the predicted cut-off value of ONSD that means intracranial pressure higher than $20 \mathrm{cmH}_{2} \mathrm{O}$ was lower than that in Caucasians [27].

The effects of $\mathrm{CO}_{2}$ pneumoperitoneum and Trendelenburg position establishment on the ONSD in sevoflurane versus propofol anesthesia are different in various studies. We found that although the ONSD increased in the sevoflurane group, the amplitude of the increase was smaller than that in the propofol group at the early stage of surgery. In the study of Robba et al. [22], the amplitude of the increase in the ONSD after sevoflurane anesthesia was consistent with that in our study. However, the studies of Kim et al. [28] and Chin et al. [29] showed that the amplitude of the increase in the ONSD after sevoflurane anesthesia was higher than that in our study. Verdonck et al. [7] believed that the ONSD remains unchanged in patients undergoing sevoflurane anesthesia.

The results of this study are generally consistent with those of Lee et al. [30], while in the first $30 \mathrm{~min}$ of operation, the results were inconsistent. The main reason may be that Lee et al. used midazolam and glinbromide before operation; on the other hand, study of Lee et al. only maintained BIS at 40-60 during the whole operation, but did not compare the BIS values between the two groups. The depth of anesthesia may affect the changes of cerebral blood flow, thus further affecting the changes of intracranial pressure and ONSD value.

The inconsistencies across different studies may be due to the lack of consistency in patients' anesthetic depth and sevoflurane blood concentration. Sevoflurane has a dominant effect on cerebral oxygen metabolism at a low concentration; while at medium and high

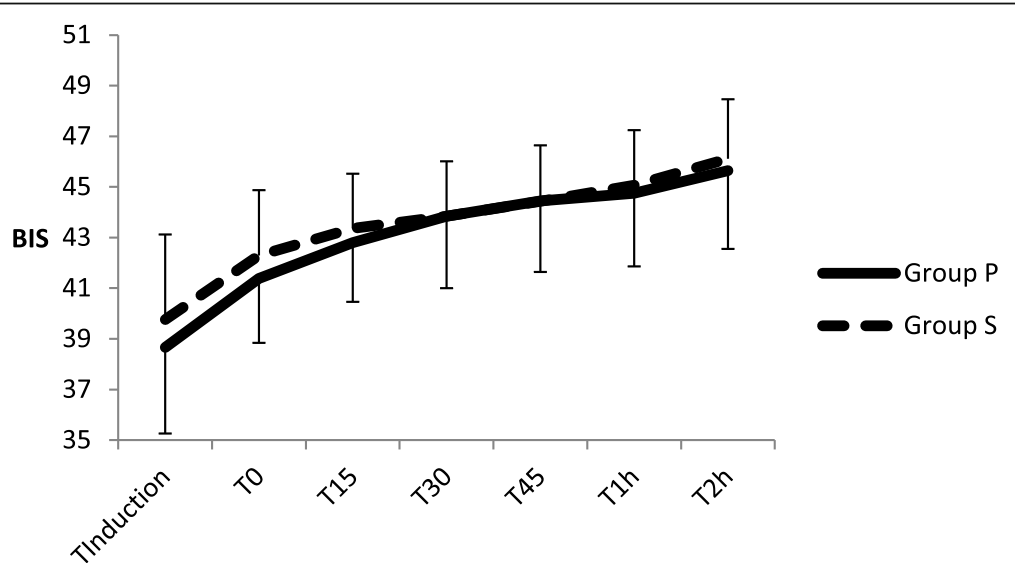

Fig. 4 Comparison of BIS at each time points between two groups. There are no significant differences between two groups at each time points (Values of $p$ were $0.093 、 0.065,0.191,1.000,0.970,0.503$ and 0.368). BIS Bispectral index 
concentrations, it has a direct vasodilatory effect [31]. Propofol reduces cerebral blood flow more because of its effect on reducing cerebral oxygen metabolism rather than direct vasoconstriction [32, 33]. Meanwhile, the ONSD can reflect intracranial pressure in real time; however, the correlation coefficient between ONSD and intracranial pressure in previous studies was $0.660-0.820$ $[19,34,35]$. Hansen et al. believed that the ONSD and intracranial pressure have an elastic nonlinear relationship [17]. In other words, the ONSD may better reflect changing trends in intracranial pressure than specific values.

We found that although the ONSD increased significantly in both groups, it returned to baseline $1 \mathrm{~h}$ after surgery. Animal studies suggest that with establishment of the $\mathrm{CO}_{2}$ pneumoperitoneum and the Trendelenburg position, intracranial pressure increased by $10 \mathrm{mmHg}$ compared to the baseline value [36]. However, Kalmar et al. [37] believe that intracranial pressure fluctuations within the physiological range are regulated by multiple mechanisms, and that the intracranial pressure increases exponentially only when these regulatory mechanisms are exhausted. Notably, the brain has a strong ability to transfer CSF to the vascular system, and when intracranial pressure increased, CSF moved intrathecally at a rate of $2 \mathrm{ml} / \mathrm{min}[38,39]$, which is also why the ONSD returned to baseline $1 \mathrm{~h}$ after surgery. On the other way, a reduction of the intracranial blood volume after termination of the steep Trendelenburg position could be the reason.

Four limitations exist in this study. First, this study did not analyse changes in the ONSD in patients with longer operative times $(>3 \mathrm{~h})$, mainly because few cases required long operative times $(>3 \mathrm{~h})$ in this study. Hansen et al. suggested that prolonged intracranial hypertension affected the reversibility of optic nerve sheath changes [17]. Therefore, we hypothesized that the duration of the increase in ONSD in patients undergoing prolonged laparoscopic gynecological surgery would be prolonged, but further studies are needed for confirmation. Second, all the patients included in this study were female patients younger than 65 years old, and further studies are needed to determine whether similar conclusions can be established for male or elderly patients. Third, in our study, sevoflurane was maintained at 1-1.5 minimal alveolar concentration (MAC) while we do not record values of end-tidal concentrations of sevoflurane (Etsevo). Animal studies suggest that cerebral blood flow may not be changed when Etsevo is 0.3-1.5MAC [40]. Artru et al. find ICP is not changed when sevoflurane is $0.5 \mathrm{MAC}, 1.0 \mathrm{MAC}$ or $1.5 \mathrm{MAC}$ in neurosurgery patients [41]. We guess that small changes in Etsevo during 0.51.5MAC may not have significant effects on cerebral blood flow. Fourth, Whiteley et al. suggest that ONSD is positively correlated with MAP [25]. In our study, there are no significant differences between Group $S$ and Group P at different time points and that is why we ignore the effect of blood pressure on ONSD.

In conclusion, we found that when comparing the two drugs, at the early stage, the ONSD postpneumoperitoneum in the propofol group was slightly larger than that in the sevoflurane group, and the difference was statistically significant. No significant difference was observed between the two groups $1 \mathrm{~h}$ after surgery.

\section{Abbreviations}

ONSD: Optic nerve sheath diameter; ASA: American Society of Anaesthesiologists; MAP: Mean arterial pressure; BIS: Bispectral index; MAC: Minimal alveolar concentration; PACU: Post-anesthetic recovery room

\section{Acknowledgements}

Not applicable.

\section{Authors' contributions}

WG, first author: Study Design, data collection, interpretation, drafting article, critical revision of the article and final approval of the version to be published. CC, co-first author: Study Design, references review, data analysis, drafting article, critical revision of the article and final approval of the version to be published. XS, second author: Study Design, critical revision of the article and final approval of the version to be published. SH, correspondance author: Study Design, data analysis, critical revision of the article and final approval of the version to be published.

\section{Funding}

Not applicable.

\section{Availability of data and materials}

The trial protocol, datasets used and/or analysed during the current study are available from the corresponding author on reasonable request.

\section{Ethics approval and consent to participate}

After approval by the ethics committee of Obstetrics and Gynaecology Hospital of Fudan University. The committee's reference number is 201805.We herein confirm written consent obtained from each patient in accordance with the Declaration of Helsinki in order to report and publish the individual patient data obtained. A written consent to participate from each patient in the current study was obtained.

\section{Consent for publication}

Not applicable.

\section{Competing interests}

The authors declare that they have no competing interests.

\section{Author details}

${ }^{1}$ Department of Anesthesia, Obstetrics and Gynecology Hospital of Fudan University, No.128, Shenyang RD, Yangpu district, Shanghai 200090, China. ${ }^{2}$ Department of Emergency and Critical Care Medicine, Shanghai General Hospital, Shanghai Jiao Tong University School of Medicine, Shanghai, China.

Received: 2 August 2020 Accepted: 11 January 2021

Published online: 27 January 2021

References

1. Fahy BG, Barnas GM, Nagle SE, Flowers JL, Njoku MJ, Agarwal M. Effects of Trendelenburg and reverse Trendelenburg postures on lung and chest wall mechanics. J Clin Anesth. 1996;8(3):236-44. https://doi.org/10.1016/09528180(96)00017-7.

2. Halverson A, Buchanan R, Jacobs L, et al. Evaluation of mechanism of increased intracranial pressure with insufflation. Surg Endosc. 1998;12:266-9. https://doi.org/10.1007/s004649900648. 
3. Lassen NA, Christensen MS. Physiology of cerebral blood flow. Br J Anaesth. 1976;48(8):719-34. https://doi.org/10.1093/bja/48.8.719.

4. Pandey R, Garg R, Darlong V, Punj J, Chandralekha AK. Unpredicted neurological complications after robotic laparoscopic radical cystectomy and ileal conduit formation in steep trendelenburg position: two case reports. Acta Anaesthesiol Belg. 2010;61:163-6 PMID: 21268573.

5. Cooke SJ, Paterson-Brown S. Association between laparoscopic abdominal surgery and postoperative symptoms of raised intracranial pressure. Surg Endosc. 2001;15:723-5. https://doi.org/10.1007/s00464-001-0004-8.

6. Kim SH, Kim HJ, Jung KT. Position does not affect the optic nerve sheath diameter during laparoscopy. Korean J Anesthesiol. 2015;68(4):358-63. https://doi.org/10.4097/kjae.2015.68.4.358.

7. Verdonck P, Kalmar AF, Suy K, et al. Optic nerve sheath diameter remains constant during robot assisted laparoscopic radical prostatectomy. PLoS One. 2014;9:e111916. https://doi.org/10.1371/ journal.pone.0111916.

8. Conti A, lacopino DG, Fodale V, Micalizzi S, Penna O, Santamaria LB. Cerebral haemodynamic changes during propofol-remifentanil or sevoflurane anesthesia: transcranial Doppler study under Bispectral index monitoring. Br J Anaesth. 2006;97(3):333-9. https://doi.org/10.1093/bja/ael169.

9. Oshima T, Karasawa F, Satoh T. Effects of propofol on cerebral blood flow and the metabolic rate of oxygen in humans. Acta Anaesthesiol Scand. 2002;46:831-5. https://doi.org/10.1034/j.1399-6576.2002.460713.x.

10. Doyle PW, Matta BF. Burst suppression or isoelectric encephalogram for cerebral protection: evidence from metabolic suppression studies. Br J Anaesth. 1999;83:580-4. https://doi.org/10.1093/bja/83.4.580.

11. Eng C, Lam AM, Mayberg TS, Lee C, Mathisen T. The influence of propofol with and without nitrous oxide on cerebral blood flow velocity and $\mathrm{CO}$, reactivity in humans. Anesthesiology. 1992;77:872-9. https://doi.org/10.1097/ 00000542-199211000-00006.

12. Matta BF, Lam AM, Strebel S, Mayberg TS. Cerebral pressure autoregulation and CO-reactivity during propofol-induced EEG suppression. Br J Anaesth. 1995;74:159-63. https://doi.org/10.1093/bja/74.2.159.

13. Drummond JC, Todd MM, Scheller MS, Shapiro HM. A comparison of the direct cerebral vasodilating potencies of halothane and isoflurane in the New Zealand white rabbit. Anesthesiology. 1986;65(5):462-7. https://doi.org/ 10.1097/00000542-198611000-00002.

14. Gupta S, Heath K, Matta BF. Effect of incremental doses of sevoflurane on cerebral pressure autoregulation in humans. Br J Anaesth. 1997;79:469-72. https://doi.org/10.1093/bja/79.4.469.

15. Choi SH, Lee SJ, Rha KH, Shin SK, Oh YJ. The effect of pneumoperitoneum and Trendelenburg position on acute cerebral blood flow-carbon dioxide reactivity under sevoflurane anesthesia. Anesthesia. 2008;63(12):1314-8. https://doi.org/10.1111/j.1365-2044.2008.05636.x.

16. Killer HE, Laeng HR, Flammer J, Groscurth P. Architecture of arachnoid trabeculae, pillars, and septa in the subarachnoid space of the human optic nerve:anatomy and clinical considerations. Br J Ophthalmol. 2003;87(6):77781. https://doi.org/10.1136/bjo.87.6.777.

17. Hansen HC, Lagrèze W, Krueger $\mathrm{O}$, Helmke K. Dependence of the optic nerve sheath diameter on acutely applied subarachnoidal pressure-an experimental ultrasound study. Acta Ophthalmol. 2011;89(6):528-32. https:// doi.org/10.1111/j.1755-3768.2011.02159.x.

18. Maissan IM, Dirven PJ, Haitsma IK, Hoeks SE, Gommers D, Stolker RJ. Ultrasonographic measured optic nerve sheath diameter as an accurate and quick monitor for changes in intracranial pressure. J Neurosurg. 2015;123(3): 743-7. https://doi.org/10.3171/2014.10.JNS141197.

19. Wang $L J$, Yao $Y$, Feng $L S$, et al. Noninvasive and quantitative intracranial pressure estimation using ultrasonographic measurement of optic nerve sheath diameter. Sci Rep. 2017;7(2):42063. https://doi.org/10.1038/srep42063.

20. Lochner $\mathrm{P}$, Coppo L, Cantello R, et al. Intra- and interobserver reliability of transorbital sonographic assessment of the optic nerve sheathdiameter and optic nerve diameter in healthy adults. J Ultrasound. 2014;19(1):41-5. https://doi.org/10.1007/s40477-014-0144-z.

21. Hassen GW, Bruck I, Donahue J, et al. Accuracy of optic nerve sheath diameter measurement by emergency physicians using bedside ultrasound. J Emerg Med. 2015;48(4):450-7. https://doi.org/10.1016/j. jemermed.2014.09.060.

22. Robba C, Cardim D, Donnelly J, et al. Effects of pneumoperitoneum and Trendelenburg position on intracranial pressure assessed using different non-invasive methods. Br J Anaesth. 2016;117(6):783-9. https://doi.org/10. 1093/bja/aew356.
23. Werner C, Hoffman WE, Baughman VL, Albrecht RF, Schulte J. Effects of sufentanil on cerebral blood flow, cerebral blood flow velocity, and metabolism in dogs. Anesth Analg. 1991;72:177-81. https://doi.org/10.1213/ 00000539-199102000-00006.

24. Smith KJ, Wong LE, Eves ND, et al. Regional cerebral blood flow distribution during exercise: influence of oxygen. Respir Physiol Neurobiol. 2012;184(1): 97-105. https://doi.org/10.1016/j.resp.2012.07.014.

25. Whiteley JR, Taylor J, Henry M, Epperson TI, Hand WR. Detection of elevated intracranial pressure in robot-assisted laparoscopic radical prostatectomy using ultrasonography of optic nerve sheath diameter. J Neurosurg Anesthesiol. 2015;27(2):155-9. https://doi.org/10.1097/ANA. 0000000000000106.

26. Blecha S, Harth M, Schlachetzki F, et al. Changes in intraocular pressure and optic nerve sheath diameter in patients undergoing robotic-assisted laparoscopic prostatectomy in steep $45^{\circ}$ Trendelenburg position. BMC Anesthesiol. 2017;17(1):40. https://doi.org/10.1186/s12871-017-0333-3.

27. Wang $L$, Feng $L$, Yao $Y$, et al. Optimal optic nerve sheath diameter threshold for the identification of elevated openingpressure on lumbarpuncture in a Chinese population. PLoS One. 2015;10(2):e0117939. https://doi.org/10.1371/ journal.pone.0117939.

28. Kim MS, Bai SJ, Lee JR, Choi YD, Kim YJ, Choi SH. Increase in intracranial pressure during carbon dioxide pneumoperitoneum with steep trendelenburg positioning proven by ultrasonographic measurement of optic nerve sheath diameter. J Endourol. 2014;28(7):801-6. https://doi.org/ 10.1089/end.2014.0019.

29. Chin JH, Seo H, Lee EH, et al. Sonographic optic nerve sheath diameter as a surrogate measure for intracranial pressure in anesthetized patients in the Trendelenburg position. BMC Anesthesiol. 2015;15:43. https://doi.org/10. 1186/s12871-015-0025-9.

30. Lee YY, et al. Optic nerve sheath diameter changes during gynecologic surgery in the Trendelenburg position: comparison of propofol-based total intravenous anesthesia and sevoflurane anesthesia. Anesth Pain Med. 2019; 14:393-400.

31. Doe A, Kumagai M, Tamura Y, Sakai A, Suzuki K. A comparative analysis of the effects of sevoflurane and propofol on cerebral oxygenation during steep Trendelenburg position and pneumoperitoneum for robotic-assisted laparoscopic prostatectomy. J Anesth. 2016;30(6):949-55. https://doi.org/10. 1007/s00540-016-2241-y

32. Holzer A, Winter W, Greher M, et al. A comparison of propofol and sevoflurane anesthesia: effects on aortic blood flow velocity and middle cerebral artery blood flow velocity. Anesthesia. 2003;58(3):217-22. https:// doi.org/10.1046/j.1365-2044.2003.03041.x.

33. Laaksonen L, Kallioinen M, Långsjö J, et al. Comparative effects of dexmedetomidine, propofol, sevoflurane, and S-ketamine on regional cerebral glucose metabolism in humans: a positron emission tomography study. Br J Anaesth. 2018;121(1):281-90. https://doi.org/10. 1016/j.bja.2018.04.008.

34. Raffiz M, Abdullah JM. Optic nerve sheath diameter measurement: a means of detecting raised ICP in adult traumatic and non-traumatic neurosurgical patients. Am J Emerg Med. 2017;35(1):150-3. https://doi.org/10.1016/j.jem. 2016.09.044.

35. Padayachy LC, Padayachy V, Galal U, Gray R, Fieggen AG. The relationship between transorbital ultrasound measurement of the optic nerve sheath diameter (ONSD) and invasively measured ICP in children: part I: repeatability, observer variability and general analysis. Childs Nerv Syst. 2016;32(10):1769-78. https://doi.org/10.1007/s00381016-3067-5.

36. Tatebayashi K, Asai Y, Maeda T, Shiraishi Y, Miyoshi M, Kawai Y. Effects of head-down tilt on the intracranial pressure in conscious rabbits. Brain Res. 2003:977(1):55-61. https://doi.org/10.1016/s0006-8993(03)02723-9.

37. Kalmar AF, Dewaele F, Foubert L, et al. Cerebral haemodynamic physiology during steep Trendelenburg position and $\mathrm{CO}(2)$ pneumoperitoneum. Br J Anaesth. 2012;108(3):478-84. https://doi.org/10. 1093/bja/aer448.

38. Eklund A, Smielewski P, Chambers I, et al. Assessment of cerebrospinal fluid outflow resistance. Med Biol Eng Comput. 2007;45(8):719-35. https://doi. org/10.1007/s11517-007-0199-5.

39. Kalmar AF, De Ley G, Van Den Broecke C, Van Aken J, Struys MM, et al. Influence of an increased intracranial pressure on cerebral and systemic haemodynamics during endoscopic neurosurgery: an animal model. $\mathrm{Br} J$ Anaesth. 2009;102(3):361-8. 
40. Kimme P, Ledin T, Sjöberg F. Dose effect of sevoflurane and isoflurane anesthetics on cortical blood flow during controlled hypotension in the pig. Acta Anaesthesiol Scand. 2007;51(5):607-13.

41. Artru AA, Lam AM, Johnson JO, Sperry RJ. Intracranial pressure, middle cerebral artery flow velocity, and plasma inorganic fluoride concentrations in neurosurgical patients receiving sevoflurane or isoflurane. Anesth Analg. 1997;85(3):587-92.

\section{Publisher's Note}

Springer Nature remains neutral with regard to jurisdictional claims in published maps and institutional affiliations.

Ready to submit your research? Choose BMC and benefit from:

- fast, convenient online submission

- thorough peer review by experienced researchers in your field

- rapid publication on acceptance

- support for research data, including large and complex data types

- gold Open Access which fosters wider collaboration and increased citations

- maximum visibility for your research: over $100 \mathrm{M}$ website views per year

At $\mathrm{BMC}$, research is always in progress.

Learn more biomedcentral.com/submissions 